\title{
Growth reactions of carnation, measured by net photosynthesis, on different air contents of the soil
}

\author{
A. L. M. van Wijk and J. Buitendijk \\ Institute for Land and Water Management Research (ICW), Wageningen, \\ the Netherlands
}

Received 7 November 1969

\begin{abstract}
Summary
An experiment concerning the influence of soil aeration on the growth of carnation (Dianthus caryophyllus L.) in glasshouses is described. The growth reaction on different levels of air content of the soil and on lowering these levels further was determined by measuring the net photosynthesis of the plant. A decrease of soil aeration was immediately followed by a reduction of photosynthesis. The higher the light intensity, the larger this reduction. It appeared that an obvious reduction in photosynthesis can only be expected on clear days in summer. Increase of soil aeration to the initial air contents was accompanied with a recovery of photosynthesis. The dry matter production was about equal at all soil air contents.
\end{abstract}

\section{Introduction}

In floriculture under glass much care is paid to soil tillage at the start of a crop because of the intensive character of the cultures, which demands a high soil moisture content to ensure an optimum water uptake at the high level of fertilization, and as it mostly concerns a culture over several years, through which during the growth a repair of soil structure by tillage is impossible. Since one grows crops in floriculture at low soil moisture stresses, the air content of the soil is the physical factor which can be first in the minimum. Loosening the soil and mixing it with organic material are meant to influence the soil structure via a modification of the porosity, the pore distribution and the distribution of water and air over this pore volume. An answer to the question what the effect of soil tillage must or possibly may be, can be given only when knowledge is present about the requirements of the crop regarding physical properties as water and air content of the soil.

The reaction of carnation (Dianthus caryophyllus L.) on the air content of the soil was subject of research in a pot experiment going for eighteen months on a 'semipractical scale'. During this experiment the differences in growth and flower production seemed to be less great than might have been expected on the basis of the great differences in air content of the soil. For this reason a second pot experiment was carried out under more conditioned circumstances and with a duration of three months, aimed to give more evidence in this regard. This experiment will be discussed here. The influence of air content and the effect of lowering it on the growth of carnation, measured by photosynthesis, were the subject of research. Attention was only paid to a possible difference in growth and not to a difference in flower production. 


\section{Material and method}

Three levels of air content, 20, 10 and $5 \%(\mathrm{v} / \mathrm{v})$, were applied in the experiment. The values of 10 and $5 \%$ were chosen, since from the other mentioned experiment it appeared that the plant roughly starts to react in this range of air content. Differences in air content of the same soil can be obtained either by changing the soil moisture content at the same porosity or by varying the pore volume of the soil. The latter gives the possibility to vary the air content at about the same moisture stress, getting rid of a variable which can influence the growth too.

The soil used was a heavy clay $(56 \%<16 \mu \mathrm{m}, 35 \%<2 \mu \mathrm{m}, 38 \%$ humus) with aggregates smaller than $10 \mathrm{~mm}$. In a laboratory test the chosen air content levels of 20,10 and $5 \%(\mathrm{v} / \mathrm{v})$ could be realized at pore volumes of 52.3, 46.4 and 41.4 and a moisture stress of $50 \mathrm{~cm}$ water. At the same time the relationship between soil moisture stress and water content was determined at the three densities. According to the densities found, the pots $(20 \times 20 \times 25 \mathrm{~cm})$ were filled in separate layers of $2 \mathrm{~cm}$, moistened to the moisture content calculated from the desorption curve, and covered with a layer of peat litter of $2.5 \mathrm{~cm}$ to prevent evaporation from the soil surface. In each pot two selected carnation cuttings (William Sim, stock II) were planted. The experiment included thirty pots: 14 pots with 20,10 with 10 and 6 with $5 \%(\mathrm{v} / \mathrm{v})$ of air in the soil. During the growth in the glasshouse (20 April-1 July 1969) the water loss by transpiration was filled up each two days, and during the three weeks of photosynthesis measurement in a growth chamber every day.

The experiment consisted of two parts, viz growth of the plants at 20,10 and $5 \%$ of air ended with a comparative measurement of photosynthesis per pot, and a comparison of the growth reaction, measured via photosynthesis, of plants grown at the mentioned air contents on a sudden lowering of it and on the time during which the low air content was maintained.

At the end of the growth in the glasshouse (maximum day temperature $20^{\circ} \mathrm{C}$ ) the plants were transported to a controlled growth chamber (temperature $25^{\circ} \mathrm{C}$, light intensity $0.10 \mathrm{cal} \mathrm{cm}^{-2} \mathrm{~min}^{-1}$, day length 16 hours). After three days the net photosynthesis of the plants was measured. From an orientating measurement it appeared that a lowering of air content from 20 to 15 and $10 \%$, respectively, during two days, did not result in a decrease of the net photosynthesis. Therefore the air contents were all lowered to 5 and $2.5 \%$, respectively, by means of a stepwise increase of the moisture content (calculated from the desorption curve). So five series of low air contents were obtained: from 20 to 5 and $2.5 \%$, respectively, from 10 to 5 and $2.5 \%$, respectively, and from 5 to $2.5 \%$. During the next sixteen days the net photosynthesis of each pot was measured each two days and then after 5 days still two times. During the total period of three weeks the air content of some pots of each series was increased to its original level by not watering the plants. This was done to see to what extent a possible reduction of photosynthesis was followed by an increase due to an increase in soil air content at a later moment.

Photosynthesis was measured according to the technique applied and described by Nunes, Bierhuizen and Ploegman (1968). ${ }^{1}$ The surface of the pot was covered with two perspex plates, adjusted to each other. In the plates two holes for the plants were saved. The plants were enclosed by a perspex container (height $56.5 \mathrm{~cm}$, diameter

1 We are much indebted to Prof. Dr J. F. Bierhuizen and Mr C. Ploegman Ing. of the Division of Biohydrology of our Institute for their advice on this matter. 
$19.5 \mathrm{~cm}$, capacity 16.5 1). Against leakage the system was sealed off with buccarit. The air in the container was changed about two times per minute with air from the outside at a rate of $271 \mathrm{~min}^{-1}$. A gas sample was withdrawn at a rate of $11 \mathrm{~min}^{-1}$ from the incoming and the outcoming air and transported through nylon tubes to a gas analyser. After drying of the air the difference between $\mathrm{CO}_{2}$ concentration of incoming and outcoming air was measured and registered. The principle of analysis by the applied URAS analyser is based on an absorption of infrared light by $\mathrm{CO}_{2}$. During measurement the plants have been grown under Philips T.L.M.F. 140W lamps at a light intensity of $0.10 \mathrm{cal} \mathrm{cm}^{-2} \mathrm{~min}^{-1}$. The measurements of photosynthesis proper were performed under Philips H.P.L.R. $400 \mathrm{~W}$ mercury vapour pressure lamps at three light intensities: $0.20,0.34$ and $0.45 \mathrm{cal} \mathrm{cm}^{-2} \mathrm{~min}^{-1}$, measured $40 \mathrm{~cm}$ above the surface of the pot. Variation in light intensity provided the possibility to acquire information about the influence of soil air at different levels of net photosynthesis.

\section{Discussion of results}

Aeration of the soil

Besides data about volume percentages of air derived from the desorption curves, data were collected during the periods of growth and measurement on the $\mathrm{O}_{2}$ content of soil air and the oxygen diffusion rate (O.D.R.) to a platinum electrode stuck into the soil (Lemon and Erickson, 1951, 1955) to characterize soil aeration. The oxygen content of soil air gives an impression about the transport possibilities of $\mathrm{O}_{2}$ over a long distance via the gas phase, the O.D.R. about the transport of oxygen over small distances directly to the root surface. The $\mathrm{O}_{2}$ content of soil air has been measured by analysis of a gas sample withdrawn from the soil. The platinum electrode applied for the measurement of O.D.R. is meant to be an imitation of an oxygen consuming root. The rate of diffusion is highly influenced by the water content of the soil, in fact the thickness of the water film surrounding the electrode or root, as the diffusion of oxygen through air is $10^{4}$ times faster than through water.

During growth there was no difference in $\mathrm{O}_{2}$ content of the soil at air contents of 20 and $10 \%$. The oxygen diffusion rate was much lower at $10 \%$ of air, but not yet limiting for good growth (Table 1). Only plants grown at $5 \%(\mathrm{v} / \mathrm{v})$ of air in the

Table 1 Some characteristics of the soil in the experiment during growth and measurement periods

\begin{tabular}{|c|c|c|c|c|c|}
\hline & $\begin{array}{c}\text { Air content } \\
(\%)\end{array}$ & $\begin{array}{l}\text { Porosity } \\
\text { (\%) }\end{array}$ & $\begin{array}{c}\text { Moisture stress } \\
\quad(\mathrm{cm} \text { water })\end{array}$ & $\begin{array}{c}\mathrm{O}_{2} \text { content } \\
(\%)\end{array}$ & $\begin{array}{c}O . D . R \\
\left(10-8 \mathrm{~g} \mathrm{O}_{2}\right. \\
\mathrm{cm}-2 \text { min-1) }\end{array}$ \\
\hline \multirow[t]{3}{*}{ Growth } & 20 & 51.3 & 55 & 20.6 & 59 \\
\hline & 10 & 46.4 & 40 & 20.3 & 38 \\
\hline & 5 & 41.4 & 50 & 10.3 & 22 \\
\hline \multirow[t]{5}{*}{ Measurement } & $20 \rightarrow 5$ & 51.3 & 10 & 19.4 & 20 \\
\hline & $20 \rightarrow 2.5$ & 51.3 & 2.5 & 17.6 & 17 \\
\hline & $10 \rightarrow 5$ & 46.4 & 10 & 19.0 & 29 \\
\hline & $10 \rightarrow 2.5$ & 46.4 & 5 & 14.5 & 21 \\
\hline & $5 \rightarrow 2.5$ & 41.4 & 20 & 7.1 & 22 \\
\hline
\end{tabular}


soil were subjected to less favourable soil aeration as the figures of $\mathrm{O}_{2}$ concentration and O.D.R. demonstrate. Since the differences in water content were only small, the decrease of O.D.R. shows the effect of soil density on the oxygen diffusion rate. At $5 \%$ of air in the soil the small surface available for diffusion (the gas-filled pores) brought about the sharp reduction of $\mathrm{O}_{2}$ concentration, together with the high percentage of small pores due to the soil compaction through which the diffusion path could easily be blocked by water.

After lowering the air content during the measuring period to 5 and 2.5 vol. $\%$, respectively, the reduction of the $\mathrm{O}_{2}$ concentration was only small at higher pore volumes in spite of the soil being near saturation. The rather flat shape of the desorption curve of both these soils in the low suction range points to the presence of large pores which are emptied already at a low suction and which could be responsible for a good exchange of oxygen. The $\mathrm{O}_{2}$ content of the soil with initially $5 \%(\mathrm{v} / \mathrm{v})$ of air and later on $2.5 \%$ is decreased still more. The soil aeration does not appear to be completely characterized by air content, data about the oxygen transport possibilities as $\mathrm{O}_{2}$ content and oxygen diffusion rate are also required. A change in air content does not need to be associated with a proportional change in the possibilities of oxygen transport.

Lowering of the air content of the soil due to an increase of the soil moisture content is accompanied by a decrease of O.D.R. values to a critical level. Various authors give an O.D.R. of $20 \times 10^{-8} \mathrm{~g} \mathrm{O}_{2} \mathrm{~cm}^{-2} \mathrm{~min}^{-1}$ as limiting for root growth (for sugar beet Wiersma and Mortland, 1953 ; for cotton, sunflower and barley Letey et al., 1961, 1962). Depending on the growth stage one noticed a difference in reaction on the O.D.R.

Root examination at the end of our experiment furnished an equal rooting depth and intensity for plants grown at 20 and $10 \%(\mathrm{v} / \mathrm{v})$ of soil air. Plants grown at $5 \%$ of air had a far less intensive and deep root system. Independent of the initial air content a decrease of air content to 5 and $2.5 \%$, respectively, involved only a slight mortality of roots, at least when considering the color of the roots.

\section{Reaction of growth on the air content of the soil}

Because of their large number, of their great difference in dimension and of the rolling up of the leaves, the total leaf surface involved in photosynthesis was not measurable. The results of measurements concerning photosynthesis at the three light intensities and soil air levels have therefore been related to the photosynthesis of plants grown at $20 \%$ of air, measured at the highest light intensity. Fig. 1 shows that the influence of the air content of the soil on the growth of carnation varies with light intensity. At low light intensity, and thus at low net photosynthesis, there is no influence of aeration. The higher the level of photosynthesis, the more important is air content for growth. At the highest light intensity the net photosynthesis at air contents of 10 and $5 \%$ is 13 and $25 \%$ lower, respectively, than at $20 \%$ of air.

The relation between soil aeration and photosynthesis is an indirect one and is highly determined by the influence of aeration on the absorption of water by the roots which is initiated and controlled by transpiration. The uptake of $\mathrm{CO}_{2}$ by plant leaves is controlled by the stomatal aperture which is determined primarily by the water balance of the plant. Vaadia et al. (1961) point out a stronger dependence of stomatal movement on transpiration than on photosynthesis. Experimental data cited by de Wit (1958) indicate that there is a fairly strong similarity in the reaction of photosynthesis and transpiration on drought and flooding. Under steady state conditions the loss of 


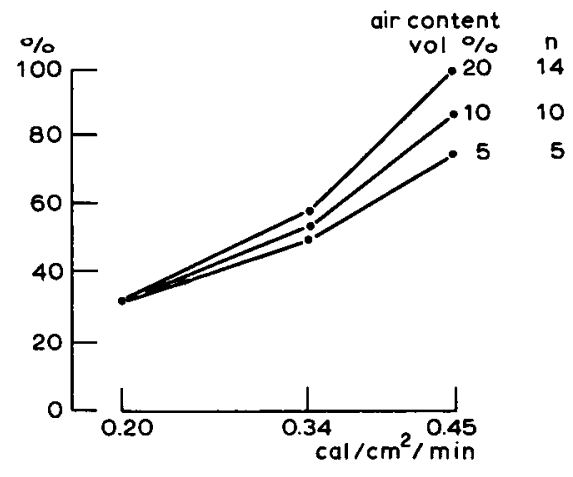

Fig. 1 The influence of the air content of the soil on net photosynthesis of carnation at three light intensities (cal $\mathrm{cm}^{-2} \mathrm{~min}^{-1}$ ) in \% of the one at $20 \%$ air content and the highest light intensity; $n=$ number of pots.

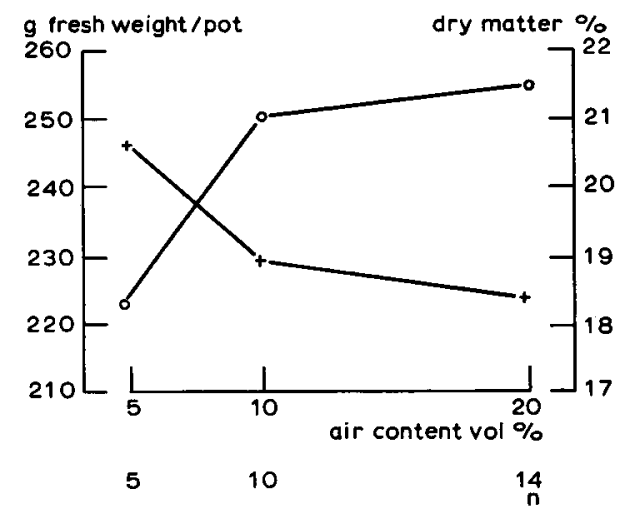

Fig. 2 The influence of the air content of the soil on the production of fresh weight (o) and the dry matter percentage $(+) ; n=$ number of pots.

water by transpiration is constant and depends on the balance between three processes: the absorption of water by the roots, the transport of water through the plant and the evaporation from the leaf surface. A failure in one of these processes, for example an increase of the resistance to absorption of water by a change in permeability of the roots, gives a higher resistance to the flow of water into the root and is accompanied by a shifting of the balance and a change in the transpiration rate. The possibility to regulate the stomatal aperture offers the plant an adaptability for growing under changing conditions and for reorganizing its water balance. Changes in stomatal aperture influence, however, the rate of $\mathrm{CO}_{2}$ uptake too and thus photosynthesis.

Bad aeration may influence the metabolic processes in the root cells and may decrease the permeability of the root tissues (Mees and Weatherley, 1957; Rijtema, 1965). Inadequate aeration reduces not only the root quantity but also retards the growth rate of the roots through which the overall permeability of roots is reduced since the unsuberized zone of rapidly growing roots is longer compared to slowly growing roots (Letey et al., 1961). The effect of air content on photosynthesis at the three light intensities is connected with the transpiration rate at each light level. A rough estimate of evaporation indicates that the light intensities of $0.20,0.34$ and $0.45 \mathrm{cal} \mathrm{cm}^{-2} \mathrm{~min}^{-1}$ correspond with transpiration rates of $3.3,5.6$ and $7.3 \mathrm{~mm}$ day-1 assuming a day-length of 16 hours. At the highest transpiration rate poor aeration may be rather limiting water absorption by way of a reduction of the root permeability with all consequences for photosynthesis.

The fresh weight of the plants is obviously reduced at air contents smaller than $10 \%$ (Fig. 2). The lower fresh matter production at air contents of 10 and $5 \%$ was 2 and $13 \%$, respectively, of the production at $20 \%$. However the dry matter percentage increases with poor soil aeration which results in small differences between the dry matter productions, namely $47.0,47.4$ and $45.9 \mathrm{~g}$ per pot at 20,10 and $5 \%$ of soil air, respectively. In spite of the great differences between the air contents, the dry matter production of plants grown at $5 \%$ of air was only $2 \%$ smaller than the pro- 
duction at $20 \%$. A calculation of the mean light intensity during the growing period in the glasshouse with a reduction of $30 \%$ for transmission, gave $0.21 \mathrm{cal} \mathrm{cm}^{-2} \mathrm{~min}^{-1}$. Fig. 1 indicates that at this light intensity the air content of the soil does not influence the net photosynthesis and so the dry matter production of carnation is not affected either.

Reaction of growth on lowering of the air content of the soil

Data about net photosynthesis collected after lowering of the air content were expressed as a percentage of the net photosynthesis measured at the initial air contents of 20,10 and $5 \%$. A possible increase of the leaf surface in the three weeks during which the photosynthesis was measured, was not taken into account. Because of the low light intensity $\left(0.10 \mathrm{cal} \mathrm{cm}^{-2} \mathrm{~min}^{-1}\right)$ at which the plants were grown, the increase of the total surface of leaves will not have been large, however. A lowering of the air content from 20,10 and $5 \%$ to 5 and $2.5 \%$, respectively, is immediately followed by a reduction of net photosynthesis (Fig. 3). After this reduction the photosynthesis settled around a constant level. A further decrease did not occur during the period of measurement. The fluctuations around the constant level have probably been brought
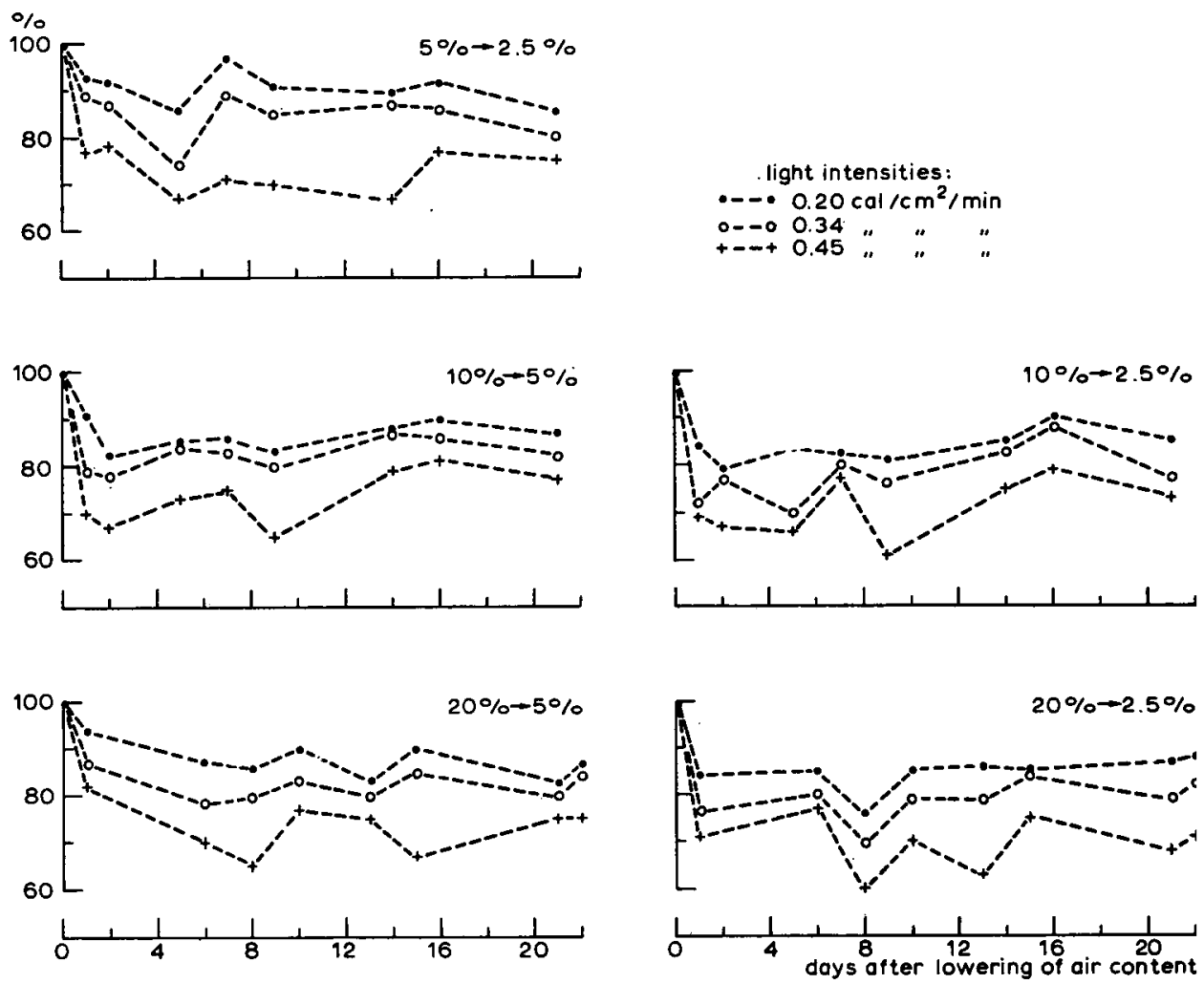

Fig. 3 The course of net photosynthesis following a decrease of the air contents from 20, 10 and $5 \%(v / v)$ to 5 and $2.5 \%$, respectively, at three light intensities. The data have been expressed as percentages of the photosynthesis at the initial air content. 
about by the not always equal arrangement of the plant leaves in the perspex container at each measurement.

The stabilization of photosynthesis after the sudden decrease of soil air content may be explained from the connection between photosynthesis and transpiration. By worsening of the aeration the resistance to water flow through the root increases due to a decrease of permeability of the root tissue. The plant adapts his water balance to the changed water absorption and adjusts it to another constant level when after the decrease in air content a steady state is reached again. For the purpose the plant is equiped with a regulating mechanism to which also the movement of the stomato belongs. A change in stomatal resistance causes a change in photosynthesis. The rate of photosynthesis also will then again be stabilized at a constant level.

The largest reduction of photosynthesis occurs at the highest light intensity. The proportional decrease of photosynthesis is smaller when photosynthesis is at a lower level due to a lower light intensity (Table 2).

The fact that at the lowest light intensity a reduction in photosynthesis is found after a decrease in air content seems rather contradictory with the data for different but constant soil air contents presented in Fig. 1. The influence of the initial air content is demonstrated by the figures on the reduction of photosynthesis of plants grown at $5 \%$ of air. The decrease of air content from 5 to $2.5 \%$ influences the photosynthesis to a lesser extent, at least at the two lowest light intensities, than the photosynthesis of plants grown at more favourable soil aeration. A difference in reaction between plants cultivated at 10 and $20 \%$ of air is hardly demonstrated. This can be explained by the almost equally favourable aeration circumstances during growth, an approximately identical decrease of $\mathrm{O}_{2}$ content and O.D.R. after lowering of the air content (Table 1). The reduction of photosynthesis was a few per cents larger after a decrease of soil air to 2.5 than to $5 \%$. If a decrease of the air content to this level arises, it is important at which light intensity this occurs. Under the climatological circumstances of the Netherlands the light intensity on a clear day in June is about $0.36 \mathrm{cal} \mathrm{cm}^{-2}$ $\min ^{-1}$ averaged over the day and reckoning with a transmission of the glasshouse of $70 \%$; for an overcast day in June $0.10 \mathrm{cal} \mathrm{cm}^{-2} \mathrm{~min}^{-1}$. Values for December were: for a clear day 0.10 and for an overcast day $0.03 \mathrm{cal} \mathrm{cm}^{-2} \mathrm{~min}^{-1}$. These values are all below the highest light intensity applied in the experiment. So at a sharp decrease in air content for instance due to a too abundant watering of the crop, the reduction of photosynthesis will stay below $25 \%$. Only on clear days in summer a reduction of photosynthesis of about 15 to $20 \%$ may be expected on basis of the presented data. At the light intensities existing on overcast days in summer and on both clear

Table 2 The mean proportional reduction of net photosynthesis following a lowering of air contents of 20,10 and $5 \%(v / v)$ to 5 and $2.5 \%$ at three light intensities

\begin{tabular}{cccccc}
\hline Lowering of air content & \multicolumn{3}{c}{ Light intensity (cal cm-2 $\min -1)$} \\
\cline { 3 - 5 } & & 0.20 & 0.34 & 0.45 \\
$20 \%$ to & $5 \%$ & $13 \%$ & $18 \%$ & $26 \%$ \\
20 & 2.5 & 15 & 21 & 31 \\
10 & 5 & 14 & 18 & 27 \\
10 & 2.5 & 19 & 22 & 29 \\
5 & 2.5 & 8 & 15 & 27 \\
\hline
\end{tabular}




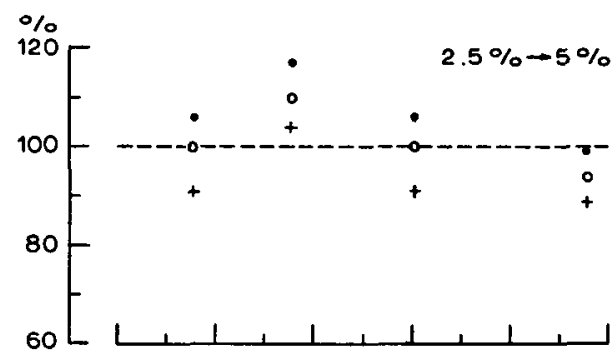

light intensities:

- $0.20 \mathrm{cal} / \mathrm{cm}^{2} / \mathrm{min}$.

0.34

$+0.45 " \ldots$
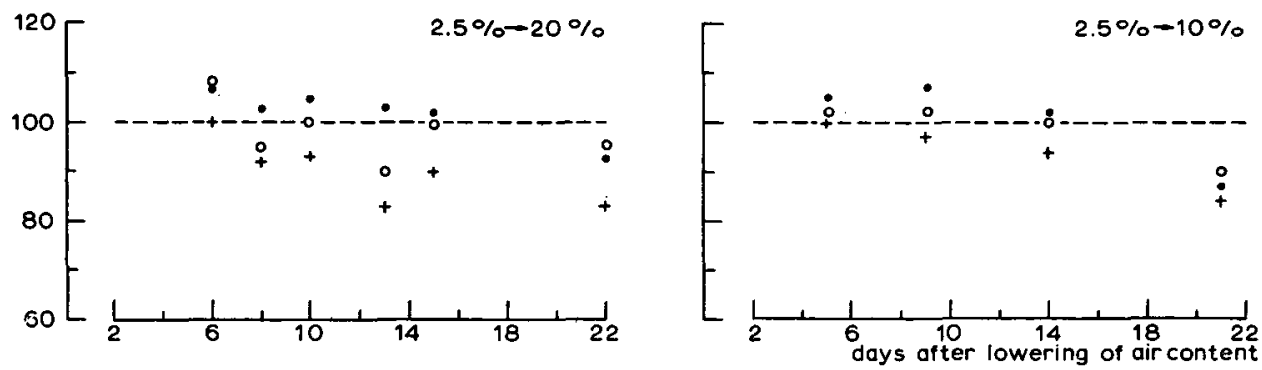

Fig. 4 The recovery of net photosynthesis as depending on the time during which the low air content was maintained. The data have been expressed as percentages of the photosynthesis at the initial air content.

and overcast days in winter only a small influence on the growth of carnation may be expected after a sharp decrease of the air content of the soil.

To find the effect of duration of the decrease of air content on the recovery rate of photosynthesis, the air content of some pots was increased to the initial level after several days at low air content by not watering the plants. The data presented in Fig. 4 are results of measurements of photosynthesis on the day at which the initial air content of the soil was reached again. To dry out the soil from 2.5 to 5,10 and $20 \%$ of air it took one to three days depending on the quantity of water to transpire. During this period the photosynthesis increased to about the same level as measured at the initial air content of the soil, at least at the two lowest light intensities and when the period during which the low air content was maintained was not longer than ten to fourteen days. After a longer duration at the low air contents the recovery of photosynthesis takes more time. At the highest light intensity the photosynthesis increased too, but at the moment of reaching the initial air content the recovery was not always complete and lasted longer according as the period of low air content was longer. The slower recovery of the photosynthesis at the highest light intensity can probably be explained by the sharper reduction of photosynthesis as a reaction on the lowering of air content at this light intensity. Generally the original photosynthesis level was reached two to five days after gaining the initial air content at the highest light intensity, provided the plants were not exposed to the low air content longer than fourteen days. The reaction of plants grown three weeks at the low soil air level was not observed up to complete recovery. 


\section{Conclusions}

1. Carnations grown during $21 / 2$ month at 20,10 and $5 \%(\mathrm{v} / \mathrm{v})$, respectively, of soil air produced an approximately equal quantity of dry matter. The production of fresh material of plants grown at 5 and $10 \%$ was 13 and $2 \%$ lower, respectively, than the one at $20 \%$ of soil air.

2. The influence of soil aeration on the growth of carnation is changing with light intensity. With an increasing quantity of light the effect of aeration on growth (photosynthesis) increases.

3. Lowering of soil air content from 20,10 and $5 \%$ to 5 and $2.5 \%$, respectively was accompanied with an immediate reduction of photosynthesis to a fairly constant level. The reduction was larger the higher the light intensity, so the higher photosynthesis. On the basis of the here presented data an obvious reduction of photosynthesis at low soil aeration should under Dutch circumstances only be expected on clear days in summer. As to the influence of the initial soil air content: the decrease of photosynthesis at lower aeration values was smaller for plants grown initially at $5 \%(\mathrm{v} / \mathrm{v})$ of soil air than for plants grown at air contents of 20 and $10 \%$, respectively.

4. An increase of the soil air content from 2.5 to 20,10 and $5 \%(\mathrm{v} / \mathrm{v})$ gave a recovery of photosynthesis. At the two lowest light intensities this recovery was complete within one to three days when the period of low soil air content did not last longer than fourteen days. At the highest light intensity the recovery of photosynthesis took more time.

\section{References}

Lemon, E. R. \& E. A. Erickson, 1952. The measurement of oxygen diffusion in the soil with platinum micro-electrode. Proc. Soil Sci. Soc. Am. 16: 160-163.

Lemon, E. R. \& E. A. Erickson, 1955. Principle of the platinum micro-electrode as a method of characterizing soil aeration. Soil Sci. 79: 383-392.

Letey, J., L. H. Stolzy, G. B. Blank \& O. R. Lunt, 1961. Effect of temperature on oxygen diffusion rates and subsequent root growth and mineral content of two plant species. Soil Sci. 92: 314-321.

Letey, J., L. H. Stolzy, G. B. Blank \& O. R. Lunt, 1961. Plant growth, water use and nutritional response to rhixosphere differentials of oxygen concentration. Proc. Soil Sci. Soc. Am. 25: $183-186$.

Letey, J., L. H. Stolzy, N. Valoras \& T. E. Szuszkiewics, 1962. Influence of oxygen diffusion rate on sunflower growth at various soil and air temperatures. Agron. J. 54: 316-319.

Letey, J., L. H. Stolzy, N. Valoras \& T. E. Szuszkiewics, 1962. Influence of soil oxygen on growth and mineral concentration of barley. Agron. J. 54:538-540.

Mees, G. L. \& P. E. Weatherley, 1957. The mechanism of water absorption by roots. Proc. Roy. Soc. Lond. B 147: 367-391.

Nunes, M. A., J. F. Bierhuizen \& C. Ploegman, 1968. Studies on productivity of coffee. I. Effect of light, temperature and $\mathrm{CO}_{2}$ concentration on photosynthesis of Coffea arabica. Acta bot. neerl. 17: 93-102.

Rijtema, P. E., 1965. An analysis of actual evapotranspiration. Agric. Res. Rep. 659. Pudoc, Wageningen, pp. 107.

Vaadia, Y., F. C. Raney \& R. M. Hagan, 1961. Plant water deficits and physiological processes. Am. Rev. Pl. Physiol. 12: 265-292.

Wiersma, D. \& M. M. Mortland, 1953. Response of sugar beets to peroxide fertilization and its relationship to oxygen diffusion. Soil Sci. 75: 355-360.

Wit, C. T. de, 1958. Transpiration and crop yields. Agric. Res. Rep. 64. Pudoc, Wageningen, pp. 88. 